Reprod. Nutr. Dévelop., 1988, 28 (1), 61-84.

\title{
Les agonistes bêta-adrénergiques. Mécanismes d'action : lipomobilisation et anabolisme
}

\author{
M. LAFONTAN, M. BERLAN $(*), M$. PRUD'HON $\left(^{* *}\right)$
}

Institut de Physiologie et

(*) Laboratoire de Pharmacologie médicale UA 644 C.N.R.S., Université Paul Sabatier, rue François-Magendie, 31400 Toulouse, France.

(**) I.N.R.A., Station de Physiologie animale E.N.S.A., Place Viala, 34060 Montpellier.

Summary. Mechanisms of action of beta-adrenergic agonists : lipomobilization and anabolism.

In this review, the results obtained in commercial livestock with certain $\beta$-adrenergic agonists (clenbuterol and cimaterol) having an anabolic potential associated with lipid mobilizing properties are considered. The first chapter summarizes major data concerning the effects of beta-agonists on growth and carcass composition in cattle, sheep and pigs. The effect of clenbuterol and cimaterol on carcass quality is to increase the deposition of protein while reducing fat accretion. Then, we briefly consider the physiology and pharmacology of the sympathoadrenal system with a special attention to the distribution and properties of $\beta$-adrenoceptors of various tissues which are putative targets for the $\beta$ adrenergic agonists.

Several mechanisms liable to be responsible for the anabolic action of these compounds are also discussed. This chapter includes the evaluation of the effects of $\beta$ agonist on central nervous system and pancreas. A special attention is devoted to their metabolic impact on adipose tissue and muscle. In isolated fat cells, $\beta$-agonists promote stimulation of lipolysis associated with reduction of lipogenesis and of insulin action. The in vitro effects on adipocytes are consistent with the in vivo effects of the compounds. Betaagonist impact on protein synthesis and muscle accretion is also discussed with reference : 1) to the vascular effects of the compounds that should modify the nutrient flow into the muscle, 2) to a reduction of proteolysis mainly observed for the moment in in vitro studies, 3 ) to the possible $\beta$-adrenergic-dependent enhancement of insulin action on the muscle. However, more direct experimental evidence is still needed to clearly assess the nature of the action(s) of such anabolic agents on muscle.

Au cours de ces dernières années plusieurs travaux ont attiré l'attention sur les effets anaboliques d'agents stimulant les récepteurs $\beta$-adrénergiques chez diverses espèces utilisées pour la production de viande (bovins, porcs, moutons, poulets). Ces agents dits "répartiteurs », administrés en traitement chronique à l'animal adulte, quelques semaines avant l'abattage, provoquent une modification 
de la composition des carcasses qui, correspond globalement à une réduction des dépôts adipeux associée à un accroissement de la masse musculaire. L'analyse des carcasses réalisée à la suite de diverses études a révélé un accroissement de la masse protéique, associé à une hydratation accrue et à une réduction nette de la masse grasse. Les implications commerciales de telles études peuvent être importantes en raison de la demande de produits carnés maigres de la part des consommateurs et des organismes de santé. De plus, il existe aussi une pression nette pour aboutir (à la réduction) et à la suppression des stéroïdes anabolisants en production animale destinée à la consommation de l'homme. L'utilisation des agonistes $\beta$-adrénergiques se présente comme une possibilité de " manipulation " pharmacologique en production animale.

Nous évoquerons et discuterons les impacts tissulaires de ces agents en insistant sur les mécanismes d'action susceptibles d'expliquer l'effet anabolique observé chez diverses espèces animales. En effet, les amines physiologiques sont impliquées dans les effets cataboliques visant à la mobilisation des réserves énergétiques.

Dans cette revue, nous examinerons d'abord, les aspects zootechniques de l'utilisation des $\beta$-agonistes chez le ruminant en insistant sur les résultats essentiels obtenus dans ce domaine. Ensuite, nous discuterons les points d'impact des $\beta$-agonistes en vue d'étayer les mécanismes susceptibles d'être impliqués dans la genèse des effets anaboliques de ce type d'agents.

\section{1 - Effets des $\beta$-agonistes sur la croissance des bovins et des ovins et la qualité des carcasses.}

Deux $\beta$-agonistes, le clenbutérol et le cimatérol, ont été utilisés à des fins zootechniques. Le clenbutérol s'est avéré efficace chez les porcs (Jones et al., 1985) et les volailles (Dalrymple et al., 1984) mais c'est essentiellement les ruminants qui ont répondu de la façon la plus spectaculaire à l'administration de ces substances.

La plupart des études (tabl. I) concernent des bovins et des ovins à l'engraissement recevant des rations riches en énergie, donc susceptibles d'avoir des dépôts adipeux développés. Toutefois, des études portent également sur des jeunes en croissance : agneaux sous la mère (Thornton et al., 1985) ou récemment sevrés (Beerman et al., 1986a), veaux en allaitement artificiel (Williams et al., 1986) ou jeunes taurillons (Hanrahan et al., 1986).

L'objectif principal des recherches est de déterminer l'effet de différentes posologies d'injection ou d'administration par voie orale du clenbutérol et du cimatérol sur la croissance, la consommation et l'efficacité alimentaire, la composition et le rendement des carcasses. L'utilisation des $\beta$-agonistes est parfois interrompue une semaine avant l'abattage.

Plus rarement, les études portent sur un ou plusieurs aspects des mécanismes ayant engendré les modifications de composition. Ainsi Thornton et al. (1985) étudient, sur des cultures d'adipocytes d'agneaux, les effets de différents 


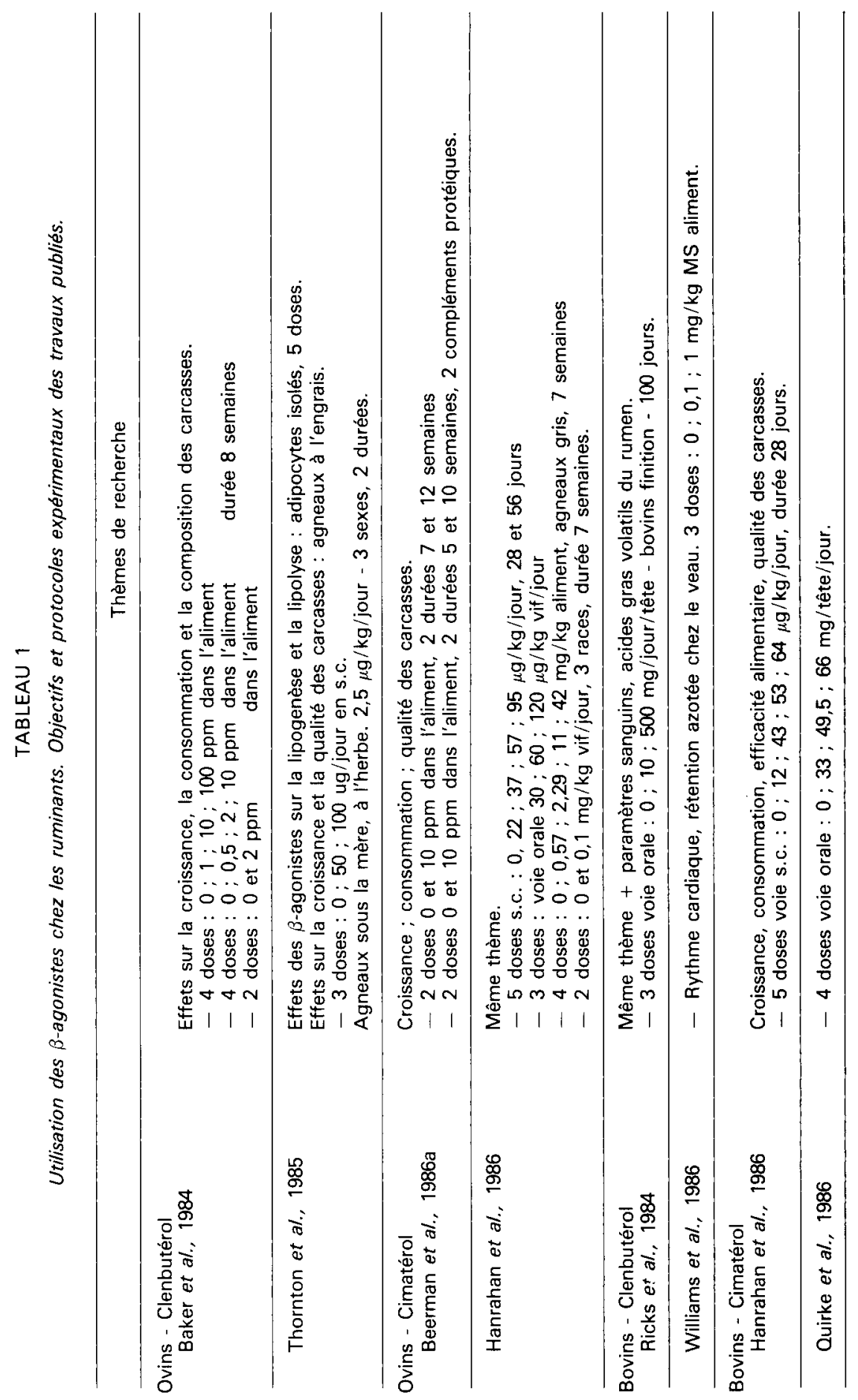


niveaux d'administration de clenbutérol dans le milieu de culture sur la lipolyse et la lipogenèse.

Ricks et al. (1984) analysent les variations d'un certain nombre de paramètres sanguins chez les bovins traités au clenbutérol : $\mathrm{Ca}^{+}+, \mathrm{P}$, transaminase glutamique oxaloacétique, acide urique, albumine, azote uréique sanguin, protéines totales, bilirubine totale, phosphatase alcaline et glucose. Ces mêmes auteurs étudient également la teneur et la répartition en acides gras volatils dans le rumen en fin de traitement.

Les autres effets des $\beta$-agonistes ont été rarement pris en considération Williams et al. (1986), ont montré que de jeunes veaux recevant du clenbutérol dans leur lait reconstitué ont un doublement de leur fréquence cardiaque pendant plusieurs heures après le repas, cette tachycardie transitoire disparaissant une fois l'adaptation au régime achevée.

\section{a) Croissance, consommation, efficacité alimentaire.}

Des accroissements de vitesse de croissance et d'efficacité alimentaire allant jusqu'à $10 \%$ et même $20 \%$ ont été observés chez les ovins et les bovins, avec du clenbutérol ou du cimatérol (Baker et al., 1984 ; Hanrahan et al., 1986) ; dans de nombreux essais, les effets ne sont cependant pas significatifs.

La consommation d'aliments est généralement peu modifiée. Toutefois, Ricks et al. (1984), utilisant de très fortes doses de clenbutérol chez des taurillons à l'engrais ( $500 \mathrm{mg} /$ tête/jour), ont enregistré un abaissement provisoire mais significatif du niveau d'ingestion d'aliments ; cet effet disparaissait après deux mois d'adaptation au régime. Plusieurs hypothèses sont émises : les $\beta$-agonistes pourraient stimuler les centres nerveux contrôlant l'ingestion à dose physiologique mais les inhiber à dose pharmacologique. Les $\beta$-agonistes pourraient également réduire la mobilité du rumen; la diminution des fermentations dans le rumen, observée avec des doses élevées du clenbutérol $184,2 \mathrm{mM}$ d'acides gras volatils contre 125,6 mM chez les témoins), serait la conséquence de cette réduction de motilité qui induirait également une baisse du niveau d'ingestion.

Un phénomène analogue de réduction de l'ingestion et de la croissance à des doses élevées de clenbutérol a également été rencontré chez le porc (Jones et al., 1985 ; Hanrahan et al., 1986) et chez le veau (Williams et al., 1986).

Les ovins semblent plus tolérants puisque des doses allant jusqu'à $3,8 \mathrm{mg} / \mathrm{kg}$ de poids vif/jour n'ont pas eu d'effet dépressif sur la croissance et l'ingestion. Selon Hanrahan et al. (1986) l'optimum serait situé, dans cette espèce, aux alentours de $0,125 \mathrm{mg} / \mathrm{kg}$ de poids vif/jour.

\section{b) Composition des carcasses.}

Toutes les expérimentations réalisées chez les ovins et bovins (tabl. 2) font apparaître des effets très marqués du clenbutérol et du cimatérol sur le développement des tissus adipeux et musculaires ainsi que sur le rendement en carcasse. Ces résultats sont indépendants du mode d'administration : incorporation dans l'aliment, injections sous-cutanées périodiques par mini-pompes, etc... Ils sont fonction des doses utilisées, avec existence fréquente d'une dose optimale audelà de laquelle les effets ne sont plus accrus. 


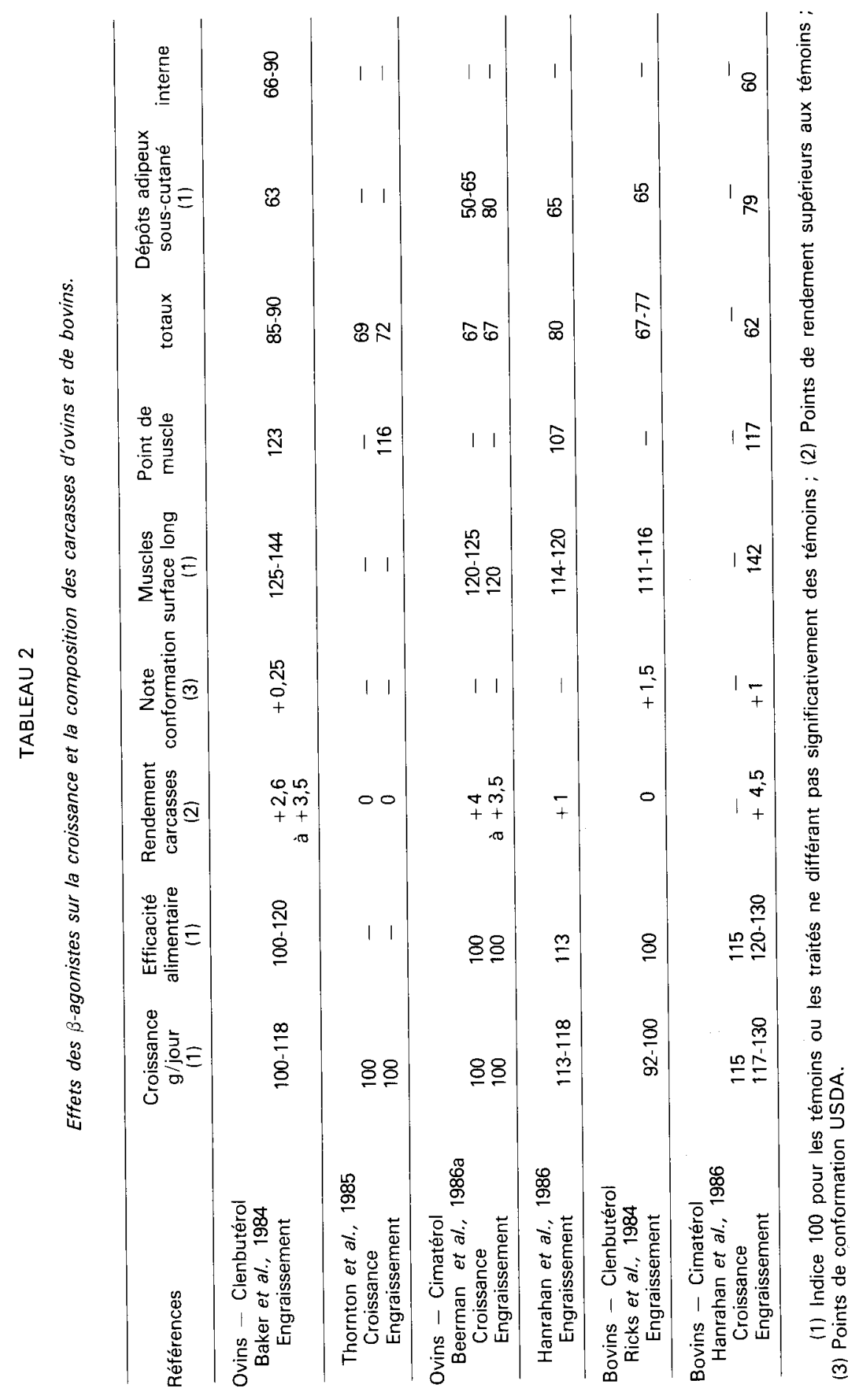


Dépôts adipeux. - La diminution des dépôts adipeux, quelle que soit leur localisation, est toujours supérieure à $10 \%$ chez les ovins et bovins. Elle peut aller jusqu'à $30 \%$ et même $40 \%$ dans certains cas (Quirke et al., 1986). Chez les bovins, Ricks et al. (1984) ont montré que les dépôts internes subissaient la même réduction que les dépôts cutanés. En se basant sur des notes de "persillé ", les auteurs émettent l'hypothèse que les dépôts intramusculaires seraient peu modifiés. Cette hypothèse n'est pas vérifiée par Quirke et al. (1986). Ces auteurs constatent une diminution très sensible de la teneur en lipides du muscle long dorsal (2,2 à $1,7 \%$ selon les doses de cimatérol contre 3,8 \% chez les témoins) ; simultanément les teneurs en eau, protéines et cendres sont significativement accrues.

Selon Thornton et al. (1985), il existerait également une modification qualitative du gras de couverture ; chez des agneaux à l'engrais traités au clenbutérol il y a moins de palmitate $(23$ vs $26 \%$ ) et plus de stéarate + oléate $(67$ vs $63 \%)$.

Chez les ovins, la réduction des dépôts adipeux semble indépendante du sexe (Thornton et al., 1985) et du type génétique (Hanrahan et al., 1986 essai IV). L'effet des $\beta$-agonistes croît de façon non linéaire avec les doses utilisées jusqu'à un seuil qu'Hanrahan et a/. (1986) situent à $0,125 \mathrm{mg} / \mathrm{kg}$ de poids vif/jour de clenbutérol chez les ovins. Thornton et al. (1985) sur adipocytes isolés de moutons mettent en évidence un double effet du clenbutérol : un effet lipolytique croissant avec la dose et une réduction de la lipogenèse. Celle-ci, mesurée par incorporation d'acétate marqué, est très forte (30 vs $160 \mu \mathrm{g} / \mathrm{g}$ lipide/h) pour les niveaux les plus faibles de clenbutérol et elle évolue peu avec la dose.

Muscles. - Qu'ils soient obtenus par la surface de section du long dorsal, la pesée de certains muscles ou le dosage des protéines, les résultats mettent en évidence un accroissement du tissu musculaire de $10 \%$ à $25 \%$ selon les essais sous l'effet du clenbutérol et du cimatérol. Tous les muscles ne sont pas également modifiés : selon Quirke et al. (1986) les muscles du quartier arrière présentent la plus forte hypertrophie, ce qui accroît d'autant la proportion de morceaux nobles. En l'absence de modifications importantes du squelette, le rapport muscle/os est amélioré.

L'origine de cet accroissement musculaire n'est pas connue. Ricks et al. (1984) enregistrent une diminution du taux d'azote uréique sanguin avec la dose de clenbutérol chez des taurillons : cela suggère une réduction du catabolisme protéique. Williams et al. (1986) mettent également en évidence, chez le veau, une amélioration de la rétention azotée, mais l'effet est peu significatif. Chez le rat, par contre, Emery et al. (1984) ont observé une amélioration de la synthèse des protéines musculaires.

Y-a-t-il multiplication ou diamètre accru des fibres ou bien accroissement du conjonctif ? Les résultats sont contradictoires. Maltin et al. (1986) étudiant l'effet du clenbutérol sur les muscles soleus et extensor longus digitorum de rats traités pendant 4 et 21 jours, obtiennent des résultats opposés. Dans le muscle soléaire, le diamètre des fibres est très significativement accru après 4 jours mais non après 21 jours. Dans l'extenseur des doigts un traitement de 21 jours modifie la répartition des fibres, au profit des fibres à un métabolisme glycolytique.

Rendement en carcasse. - Dans tous les essais, le rendement en carcasse est accru de 2 à 4 points. Cela est dû au développement musculaire qui remplace 
les dépôts adipeux ; il y aurait également une baisse du poids de la peau. Par contre, d'autres éléments du $5^{e}$ quartier sont peu modifiés : trachée, cœur, poumons, foie. Enfin, selon Quirke et al. (1986) les effets sur le rendement seraient plus marqués avec le cimatérol qu'avec le clenbutérol et davantage chez les bovins que chez les ovins.

Précisons cependant qu'aucune comparaison du clenbutérol et du cimatérol n'a été publiée à ce jour sur bovins et que le nombre d'essais réalisés chez cette espèce reste limité.

\section{II - Mécanismes d'action des $\beta$-agonistes.}

1) Distinction des diverses familles de $\beta$-récepteurs et spécificité des $\beta$-agonistes.

Les effecteurs du système nerveux autonome constituent les cibles de ce type de composés $\beta$-agonistes à effets " répartiteurs ". Nous essaierons, tout d'abord, de clarifier l'identité pharmacologique et biochimique des structures réceptrices impliquées dans la transduction des effets des $\beta$-agonistes.

Lands et $a /$. (1967) ont suggéré que l'ensemble des effets $\beta$-stimulants des catécholamines pourraient être mieux compris si l'on postulait l'existence de deux sous-types de $\beta$-adrénocepteurs : le $\beta 1$ - et le $\beta 2$-adrénocepteur.

Les techniques les plus récentes basées sur l'utilisation de radioligands ont permis de mieux déterminer quantitativement et qualitativement les propriétés des récepteurs $\beta$-adrénergiques d'un tissu ou de cellules isolées. Ainsi, la coexistence de $\beta 1$ - et $\beta 2$-adrénocepteurs a été bien démontrée dans le poumon, le cœur et différentes régions du système nerveux central chez diverses espèces de mammifères avec cependant des différences interspécifiques : les $\beta 1$-récepteurs sont plus abondants dans le ventricule cardiaque du rat et du chat que chez l'homme (mukherjee et al., 1983 ; Liang et Molinoff, 1986). Ces récepteurs seraient responsables de l'effet chronotrope positif des amines physiologiques. Les $\beta 2$-récepteurs sont prédominants dans le poumon, le cervelet, les éléments figurés du sang (plaquettes, lymphocytes) et I'hépatocyte de certaines espèces. Ces récepteurs $\beta 2$ adrénergiques constitueraient la structure, réceptrice majeure du muscle lisse, du muscle strié et du lit vasculaire de divers tissus. Dans ce domaine il faut éviter toute systématisation abusive car, pour un tissu donné, il peut y avoir des différences interspécifiques dans le sous-type de $\beta$-récepteur impliqué dans la même réponse biologique. De plus, des tissus comme le tissu adipeux, posséderaient des $\beta$-récepteurs n'entrant apparemment pas dans la classification traditionnelle (Wilson et al., 1984 ; Bojanic et al., 1984).

L'autre interprétation de la dichotomie $\beta 1$ - et $\beta 2$-adrénocepteurs a été proposée par Ariens et Simonis (1983). La nouvelle distinction a pour objectif d'insérer la classification $\beta 1-\beta 2$, qui peut paraître pas trop arbitraire, dans un contexte plus physiologique : les $\beta 1$-récepteurs seraient les récepteurs privilégiés de la noradrénaline, le neurotransmetteur des terminaisons nerveuses orthosympathiques ; ces récepteurs ont plus d'affinité pour la noradrénaline que pour l'adrénaline et sont absents dans les tissus totalement dépourvus d'innervation adrénergique tels que les éléments figurés du sang. Les $\beta 2$-récepteurs seraient les récepteurs de I'adrénaline circulante ; ils ont le statut de récepteurs " hormonaux " et sont caractéri- 
sés par leur forte affinité pour l'adrénaline et leur moindre affinité pour la noradrénaline. Ils peuvent exister dans un tissu dépourvu d'innervation adrénergique. Les tissus contenant des $\beta 2$-récepteurs et innervés posséderaient donc un mélange de récepteurs $\beta 1$ - et $\beta 2$-adrénergiques impliqués dans la genèse d'un même type de réponse; la médiation de réponses différentes n'étant pas à exclure pour le moment bien que les deux types de récepteurs soient couplés positivement à l'adénylate cyclase. De façon générale, les réponses engendrées par la stimulation des $\beta 2$-récepteurs sont peu modifiées par la dénervation chimique ou chirurgicale du tissu ou de l'organe alors que les réponses dépendant des $\beta$-1-récepteurs présentent une hypersensibilisation. Les principaux effets contrôlés par les $\beta$ récepteurs adrénergiques sont récapitulés dans le tableau 3.

Les agonistes $\beta$-adrénergiques de synthèse appartiennent à diverses familles chimiques. L'agent $\beta$-agoniste de référence, l'isoprotérénol (isoprénaline), ne possède pas de spécificité pour l'un des sous-types de $\beta$-récepteurs. Par contre, de nombreux composés susceptibles d'interagir avec plus ou moins de spécificité avec l'un des grands sous-types de $\beta$-récepteurs ont été synthétisés, d'où une

\section{TABLEAU 3}

Distribution tissulaire des récepteurs $\beta$-adrénergiques: Nature des réponses physiologiques, métaboliques et endocriniennes liées aux les $\beta$-agonistes.

\begin{tabular}{|c|c|c|}
\hline Effecteur & Type de $\beta$-récepteur & Réponse \\
\hline $\begin{array}{l}\text { Muscle lisse : } \\
\text { - vasculaire } \\
\text { - bronchique } \\
\text { - utérin }\end{array}$ & $\begin{array}{l}\beta 2 \\
\beta 2 \\
\beta 2\end{array}$ & $\begin{array}{l}\text { Relaxation. } \\
\text { Relaxation. } \\
\text { Relaxation. }\end{array}$ \\
\hline Cœur & $\beta 1 \& \beta 2$ & $\begin{array}{l}\text { Inotrope et } \\
\text { Chronotrope positifs. }\end{array}$ \\
\hline Foie & $\beta 2$ & Glycogénolyse. \\
\hline Adipocyte blanc & $\begin{array}{c}\beta 1 \& \beta 2 \\
\text { « atypique } »\end{array}$ & Stimulation de la lipolyse. \\
\hline Adipocyte brun & $\beta 1 \& \beta 2$ & $\begin{array}{l}\text { Stimulation de la lipolyse, } \\
\text { de la thermogenèse et de la } \\
\text { transcription du gène de la } \\
\text { " protéine découplante ". }\end{array}$ \\
\hline $\begin{array}{l}\text { Muscle } \\
\text { squelettique }\end{array}$ & $\beta 1 \& \beta 2$ & $\begin{array}{l}\text { Effets sur contraction, effets } \\
\text { métaboliques (lipolyse \& gly- } \\
\text { cogénolyse stim.); protéo- } \\
\text { lyse inhibée. }\end{array}$ \\
\hline Hypothalamus & $\beta 2$ & $\begin{array}{l}\text { Inhibition de la libération } \\
\mathrm{GrH} \text {. }\end{array}$ \\
\hline Hypolyse & $\beta 2$ & $\begin{array}{l}\text { Augmentation de la libéra- } \\
\text { tion } \mathrm{GH} \text {. }\end{array}$ \\
\hline Pancréas & $\beta 2$ & $\begin{array}{l}\text { Stimulation de la sécrétion } \\
\text { de l'insuline et du glucagon. }\end{array}$ \\
\hline $\begin{array}{l}\text { Eléments figurés } \\
\text { (plaquettes et } \\
\text { lymphocytes) }\end{array}$ & $\beta 2$ & $\begin{array}{l}\text { Stimulation de la production } \\
\text { d'AMPc. }\end{array}$ \\
\hline
\end{tabular}


certaine confusion dans la littérature. Parmi les agonistes $\beta$-adrénergiques, ceux décrits comme possédant des propriétés $\beta 2$-agonistes (salbutamol, sotérénol, zintérol, fénotérol, procatérol), se sont avérés capables de stimuler l'adénylate cyclase de membranes pulmonaires sans agir sur l'adénylate cyclase de membranes myocardiques. Cependant certains d'entre-eux sont des agonistes partiels susceptibles d'inhiber la stimulation de l'adénylate cyclase induite par l'isoprotérénol. II faut aussi souligner qu'il n'existe pas pour le moment d'agoniste possédant de sélectivité absolue pour un sous-type de $\beta$-récepteur.

Deux composés ont été étudiés chez les rongeurs et les mammifères domestiques, il s'agit du clenbutérol (Benzy) alcohol, 4 amino- (t-butylamino) méthyl-3,5 dichloro] et du cimatérol (CL263,780) ou anthranilonitrile-5 [1-hydroxy-2-(isopropylaminol éthyl].

Le clenbutérol, composé le plus utilisé pour le moment, est un $\beta$-agoniste doué d'effets bronchodilatateurs ; c'est un agoniste partiel qui possède une haute affinité pour les récepteurs $\beta 2$ - et une affinité moindre pour les $\beta 1$-récepteurs adrénergiques (Waldeck et Widmark, 1985). Curieusement, ce composé possède une efficacité relative d'activation des $\beta 2$ - et $\beta 1$-récepteurs veineux ou cardiaques, assez faible, par rapport au salbutamol et à l'isoprotérénol (Cohen et al., 1982). La haute potentialité agoniste de ce composé résulte plutôt de sa haute affinité pour les $\beta$-récepteurs que de son efficience à stimuler ces récepteurs. Des études complémentaires sont nécessaires afin de clarifier l'impact de ce composé sur les récepteurs adrénergiques des tissus métaboliquement actifs (tissu adipeux, muscle).

Structuralement, le clenbutérol diffère des autres agents bronchodilatateurs par le fait qu'il n'est pas une amine phénolique mais un dérivé aminé dichloré. Cette structure peut expliquer sa nette lipophilie et son inactivation limitée par la catéchol-O-méthyl transférase expliquant ainsi sa duréa d'action prolongée. Alors que la plupart des $\beta$-agonistes ne pénètrent pas dans le système nerveux central, des études récentes ont bien montré que le clenbutérol peut franchir la barrière hématoencéphalique et exercer des effets sur le système nerveux central après une administration systémique (Dooley et al., 1983; O'Donnell et Frazer, 1985).

\section{2) Mécanismes d'action des agents $\beta$-agonistes induisant une répartition des} substrats métaboliques.

Les mécanismes susceptibles de rendre compte de l'ensemble des effets de ce type d'agents " répartiteurs » ne sont pas bien définis. La diversité des points d'impact potentiels de ce type de composés permet de penser qu'ils induisent des effets plus ou moins interdépendants sur les métabolismes énergétique, lipidique et protéique. Il est raisonnable d'envisager des actions directes, par l'intermédiaire des $\beta$-récepteurs adrénergiques de l'adipocyte, du système vasculaire, du muscle et des actions indirectes médiées par l'intermédiaire du système neuro-endocrinien ou des cellules bêta-pancréatiques. Comme ces composés sont appelés à être administrés avec le régime alimentaire, il faut aussi penser à un premier point d'impact au niveau du tube digestif avec des actions sur la motricité et sur l'absorption des nutriments (Yanda et Summers, 1983). 
a) Action des $\beta$-agonistes sur le système nerveux central et sur l'activation du système hypothalamo-hypophysaire.

Certains $\beta 2$-agonistes peuvent, de façon variable selon la famille chimique considérée, franchir la barrière hématoencéphalique après administration systémique et perturber l'activité des neurones sérotoninergiques et adrénergiques (Hallberg et al., 1981 ; Lecrubier et al., 1980 ; Simon et al., 1984). II est raisonnable d'envisager que la stimulation directe des $\beta$-récepteurs centraux ou le recrutement indirect des autres familles de récepteurs adrénergiques par l'activation simultanée des neurones noradrénergiques vont avoir des répercussions fonctionnelles sur l'axe hypothalamo-hypophysaire avec des altérations de la production de l'hormone de croissance, de la prolactine, de l'ACTH, de la TSH. Nous ne pouvons pas développer ici ce volet du problème et invitons le lecteur à consulter une mise au point récente de Tuomisto et Männistö (1985) pour appréhender toutes les difficultés rencontrées dans l'approche de cette question. En ce qui concerne les effets directs des $\beta 2$-agonistes sur le système hypothalamo-hypophysaire, les données sont très limitées. La stimulation des $\beta$-récepteurs inhiberait la sécrétion d'ACTH et de $\mathrm{GH}$ alors que les $\beta$-antagonistes provoqueraient tout comme les $\alpha$ agonistes une sécrétion de ces hormones (Bluet-Pajot et al., 1980 ; 1982 ; Perkins et al., 1985). Des résultats assez discordants sont obtenus en fonction du conditionnement des animaux (anesthésié ou non anesthésié) et de l'espèce considérée. Les traitements au clenbutérol ne paraissent pas modifier notablement les taux circulants de $\mathrm{GH}$, T3 ou de prolactine chez le rat ou l'agneau (Beerman et al., 1985b).

II serait certainement important de s'assurer du franchissement de la barrière hématoencéphalique par ce type de composés bien qu'un effet central soit peu probable aux faibles doses utilisées habituellement. II faudrait également obtenir des données plus précises sur l'incidence de ces traitements aux $\beta 2$-agonistes sur le profil endocrinien des espèces présentant un intérêt en production animale en tentant de dissocier les effets aigus des réponses observées après plusieurs semaines de traitements chroniques. On doit s'interroger sur la stabilité des effets observés ainsi que sur l'existence d'une éventuelle désensibilisation des récepteurs $\beta$-adrénergiques provoquée par l'administration chronique de ces composés (O'Donnell et Frazer, 1985 ; Mogilnicka et Nielsen, 1986 ; Rothwell et al., 1987).

En plus des effets sur différents territoires encéphaliques, on ne doit pas négliger le fait qu'un $\beta 2$-agoniste peut également activer les $\beta 2$-récepteurs adrénergiques préjonctionnels (fig. 1) localisés sur les terminaisons nerveuses postganglionnaires sympathiques (Dahlöf, 1981). Lorsque ces récepteurs préjonctionnels sont stimulés, ils peuvent renforcer le contrôle sympathique de certains territoires en amplifiant la libération de noradrénaline provoquée par l'activation physiologique de la terminaison nerveuse (Majewski, 1983 ; Dahlöf et al., 1986). L'activateur physiologique serait l'adrénaline plutôt que la noradrénaline libérée au niveau de la terminaison nerveuse (Rand et Majewski, 1984). On connaît peu de choses sur les effets endocrinométaboliques entraînés par une activation chronique de cette famille de récepteurs ; ils restent à démontrer. Nous discuterons cet aspect lorsque nous aborderons la régulation de la sécrétion d'insuline par les $\beta$-agonistes. 


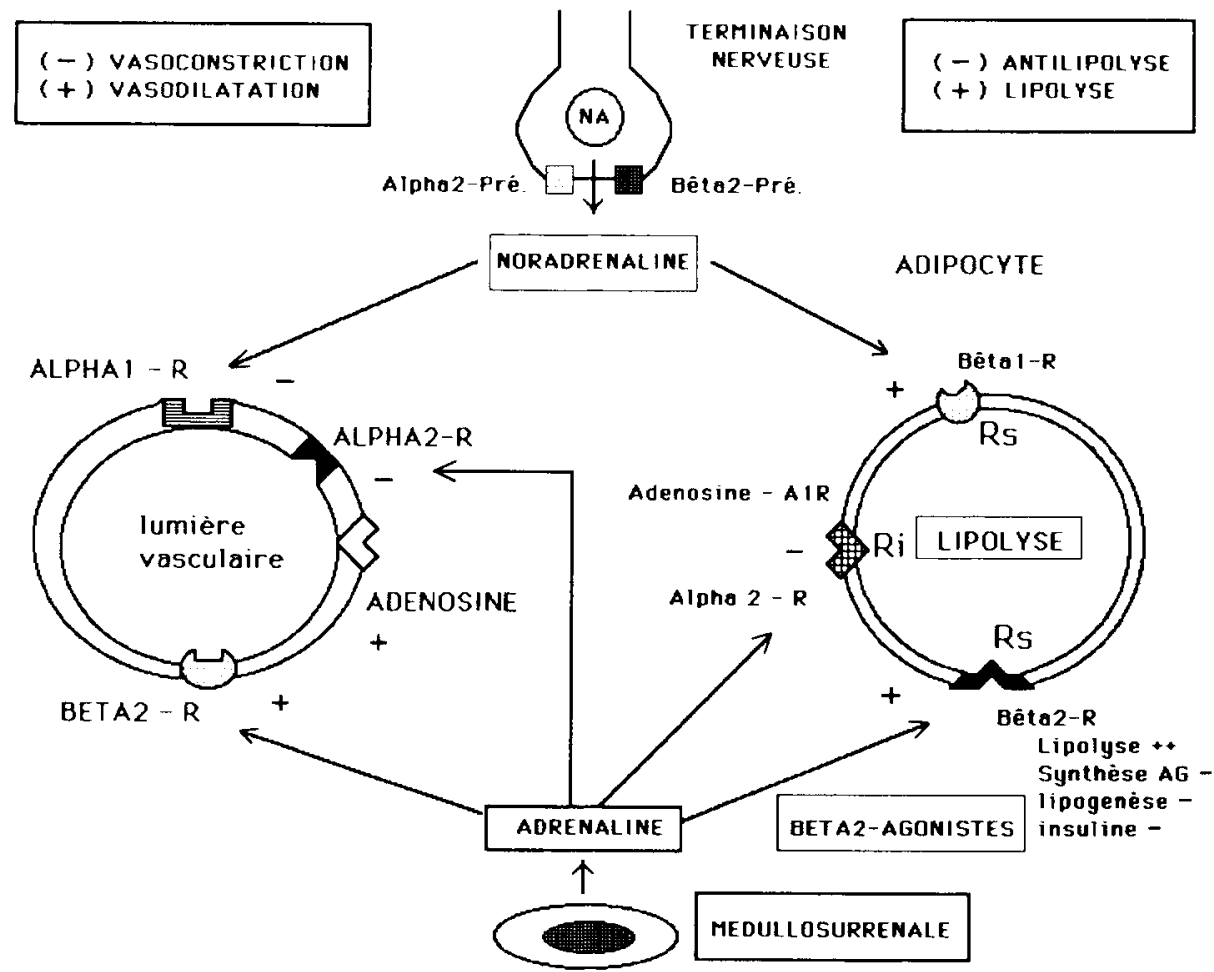

FIG. 1. - Effets réciproques des amines physiologiques et des 32 -agonistes sur l'activité lipolytique de l'adipocyte et sur le flux sanguin dans le tissu adipeux.

Les points d'impact potentiels des $\beta 2$-agonistes sur l'adipocyte, le système vasculaire et les terminaisons nerveuses postganglionnaires orthosympathiques figurent sur ce schéma. Les récepteurs adrénergiques vasculaires (alpha1, alpha2 et bêta2) adipocytaires (alpha2, bêta1 et bêta2) et présynaptiques (alpha2 et bêta2) ainsi que les récepteurs adénosine sont également représentés sur la figure. Ces divers récepteurs contrôlent la motricité vasculaire, l'activité lipolytique de l'adipocyte et la libération de la noradrénaline. Les effets sont analysés de façon plus détaillée dans le texte.

b) B2-agonistes et insulino-sécrétion.

Le système nerveux sympathique joue un rôle important dans le contrôle de l'insulino-sécrétion; la cellule bêta-pancréatique est dotée de $\beta$-et $d^{\prime} \alpha 2$ récepteurs. Les agonistes $\alpha 2$-adrénergiques inhibent la sécrétion d'insuline alors que les $\beta$-agonistes exercent un effet insulino-sécréteur chez diverses espèces animales. L'adrénaline et la noradrénaline sont connues pour stimuler les récepteurs $\alpha$-adrénergiques et donc inhiber l'insulino-sécrétion. Lorsque ces récepteurs inhibiteurs sont bloqués par un antagoniste spécifique, les amines physiologiques stimulent alors l'insulino-sécrétion. Divers $\beta$-agonistes synthétiques (isopropylnoradrénaline, salbutamol, ritodrine) stimulent la sécrétion d'insuline. Chez le chien, une perfusion -de salbutamol, agoniste $\beta 2$-adrénergique, provoque une sécrétion 
d'insuline. Cet effet n'est pas bloqué par un $\beta 1$-antagoniste spécifique tel que le practolol alors qu'il est bloqué par le propranolol (Loubatières et al., 1977). Chez les rongeurs et le veau, l'administration de $\beta$-antagonistes entraîne une chute des taux d'insuline plasmatique (Lundquist et Ericson, 1978; Ahren et Lundquist, 1984 ; Bloom et Edwards, 1985). La réponse engendrée par les $\beta$-agonistes est cependant différente de celle obtenue avec le glucose ou le carbachol (Ahren et Lundquist, 1984). Les études pharmacologiques fonctionnelles ont révélé que les $\beta$-récepteurs de la cellule bêta-pancréatique sont des $\beta 2$-récepteurs chez les rongeurs et le chien. L'effet insulino-sécréteur induit par les $\beta$-agonistes est généralement assez fugace lorsqu'ils sont administrés en aigu (i.v.) ; une étude précise des effets engendrés par leur administration par voie digestive reste à faire. Les données expérimentales concernant les effets des agents $\beta$-agonistes doués d'un pouvoir de répartition sur la sécrétion d'insuline sont encore très limitées.

Le cimatérol provoque, dans les heures qui suivent son administration, un accroissement des taux d'insuline plasmatique. Cette augmentation de l'insulinémie est contemporaine d'une augmentation de la glycémie, du taux d'acides gras libres plasmatiques et d'une réduction des taux plasmatiques d'urée (Beerman et al., 1986b). Il serait intéressant d'obtenir des données plus complètes sur la durée de ces effets ainsi que sur leur persistance éventuelle après plusieurs semaines de traitement chronique. En effet, une meilleure connaissance des impacts insuliniques de ces agents devrait permettre de mieux dissocier les effets propres de ces $\beta 2$-agonistes sur les tissus-cibles de la contribution éventuelle de l'insuline dans l'action anabolisante.

II n'existe aucune donnée fiable chez les ruminants qui permette d'affirmer ou infirmer l'existence d'effets des $\beta 2$-agonistes sur l'insulino-sécrétion; il paraît essentiel d'apporter des réponses claires à cette question. Un travail récent entrepris sur de jeunes agneaux n'a pas révélé d'effets du clenbutérol sur l'insulinémie basale. Il faut noter qu'il n'y a eu aucune exploration des capacités sécrétoires du pancréas dans ces conditions expérimentales (Beerman et al., 1985b). Une expérience pourrait consister à tester les effets des $\beta 2$-agonistes " répartiteurs " chez l'animal diabétique ou insulinoprive ; il serait intéressant d'étudier la conservation de l'effet anabolique des $\beta 2$-agonistes ou la prévention de l'effet catabolique engendré par l'état diabétique. Chez le rat, il semble que l'isoprotérénol ( $\beta$ agoniste mixte) connu pour exercer un effet anabolique sur le cœur (Gordon, 1972) et le muscle tibial, puisse conserver une grande partie de ses effets sur le cœur et le muscle squelettique en l'absence d'insuline (Deshaies et al., 1981).

\section{c) B2-agonistes et tissu adipeux.}

La réduction nette de la masse grasse observée chez les divers animaux traités chroniquement par les $\beta 2$-agonistes " répartiteurs" peut s'interpréter selon plusieurs mécanismes présentant une bonne complémentarité et susceptibles d'être activés simultanément (fig. 1):

- accroissement du flux sanguin dans le tissu adipeux par action sur les $\beta 2$ récepteurs du système vasculaire. Cet effet a été bien démontré très récemment (Rothwell et al., 1987). 
- induction d'une lipomobilisation par stimulation directe ou indirecte (activation des fibres sympathiques) des récepteurs $\beta$-adrénergiques de l'adipocyte ;

- diminution des taux de synthèse des acides gras et action antilipogénique ;

- réduction des effets de l'insuline au niveau du tissu adipeux :

- activation du tissu adipeux brun (chez les espèces possédant un tissu adipeux brun bien développé) avec stimulation de la thermogenèse et dissipation d'énergie.

Tout d'abord, en ce qui concerne les diverses espèces utilisées en production animale, les travaux accomplis sur l'adipocyte isolé ou sur des fragments de tissu adipeux ont révélé l'existence d'effets lipolytiques des amines physiologiques et du $\beta$-agoniste non spécifique, l'isoprotérénol. Les études consacrées aux effets des $\beta$-agonistes plus spécifiques sont beaucoup plus rares. Seule une étude exhaustive de ces effets a été réalisée sur le tissu adipeux du porc (Mersmann, $1984 a$ et $1984 b)$. Cette étude a révélé la particularité du tissu adipeux du porc qui semble posséder un $\beta$-récepteur difficile à insérer dans la classification habituelle. Parmi les agonistes de synthèse étudiés, seuls trois composés possédant un noyau résorcinol couplé à une chaîne latérale éthanolamine (terbutaline, fenoterol et metaproterenol) ont présenté une efficacité lipolytique, toutefois inférieure à celle de l'adrénaline. Récemment, Thornton et al. (1985) ont montré que le clenbutérol possède une activité lipolytique in vitro sur l'adipocyte isolé de mouton. Ce composé n'exerce apparemment pas d'effets lipolytiques sur l'adipocyte de poulet bien que cette espèce possède des $\beta 2$-récepteurs dont le rôle fonctionnel reste à établir (résultats non publiés). Les études sont encore très fragmentaires dans ce domaine ; la spécificité du ou des $\beta$-récepteurs de l'adipocyte blanc des ruminants et ovins a été peu étudiée jusqu'ici.

En ce qui concerne l'effet lipolytique, il est maintenant bien établi que le $\beta$ récepteur est couplé positivement à l'adénylate cyclase ; sa stimulation entraîne une activation de l'enzyme avec production d'AMP cyclique, activation d'une protéine kinase AMPc-dépendante pour aboutir à l'activation de la lipase hormonosensible et à l'hydrolyse des triglycérides stockés dans l'adipocyte (revues de Lafontan, 1985, 1986). L'adipocyte du tissu adipeux blanc de la plupart des espèces étudiées jusqu'ici semble posséder une population mixte de $\beta 1$-et $\beta 2$ récepteurs ; la proportion relative de ces deux types de sites peut varier selon le type de tissu et l'espèce considérée. La définition des proportions relatives des deux sous-types repose sur l'analyse des courbes obtenues par l'étude de la compétition de la liaison de radioligands antagonistes non spécifiques par des antagonistes froids présentant une haute spécificité pour l'un des sous-types de récepteurs ( $\beta 1$ ou $\beta 2$ ). Pour le moment, il existe encore plusieurs questions non résolues dans ce domaine. Chez le rat, par exemple, selon certains auteurs, le $\beta$ récepteur de l'adipocyte blanc serait constitué d'un mélange de $\beta 1$ - et $\beta 2$ récepteurs alors que d'autres considèrent qu'il s'agit plutôt d'un récepteur dit "atypique ", cette définition conservant toute son imprécision (Bojanic et Nahorski, 1983 ; Wilson et al., 1984). Quoi qu'il en soit, l'administration chronique de clenbutérol entraîne, chez le rat, une réduction de l'extension des dépôts adipeux blancs associée à une augmentation du tissu adipeux brun interscapulaire ; ces effets sont variables selon la souche de rats utilisée (Berne et al., 1985). 
En plus des lacunes citées dans le domaine des espèces présentant un intérêt en production animale, il faut aussi souligner la difficulté à prédire les réponses engendrées par les $\beta$-agonistes dans les tissus possédant les deux sous-types de $\beta$-récepteurs. Pour l'adipocyte, comme pour d'autres tissus, l'activité intrinsèque d'un agoniste donné peut différer selon l'espèce considérée. L'intensité de la réponse de l'adénylate cyclase aux $\beta$-agonistes dépend en partie du nombre de récepteurs mais dépend surtout de l'efficacité du couplage entre le récepteur occupé par l'agoniste et les sous-unités du système adényl-cyclasique. Ainsi il est raisonnable de penser qu'une faible proportion de récepteurs couplés très efficacement à l'adénylate cyclase peut masquer le rôle d'une plus large population de sites couplés plus faiblement mais activables par un agoniste bien spécifique.

Tout cet aspect du problème requiert des études détaillées qui devraient permettre de mieux comprendre les effets de ces $\beta$-agonistes agissant comme des facteurs de répartition des substrats.

En plus des effets lipolytiques, le clenbutérol et le cimatérol diminuent l'incorporation de l'acétate marqué dans les acides gras libres et estérifiés des adipocytes de mouton (Thornton et al., 1985) et de bovins (Miller et al., 1986). L'effet semble être plus net pour les adipocytes sous-cutanés que pour les adipocytes du tissu adipeux intermusculaire.

L'adrénaline ne mime pas les effets du clenbutérol (Miller et al., 1986) alors que divers $\beta$-agonistes (isoprotérénol, clenbutérol, $L-640,033$ et $B R L-35,135$ ) présentent une activité antilipogénique dans l'adipocyte de rat (Duquette et al., 1985).

Si I'on se réfère aux seules potentialités in vitro du clenbutérol et du cimatérol, associant un effet lipolytique à un effet antilipogénique, on peut aisément comprendre leur impact à long terme sur les réserves lipidiques des animaux. Le déséquilibre ainsi créé au niveau du tissu adipeux et la réduction de la synthèse des acides gras permettent une réorientation des glucides vers le muscle.

Une autre action remarquable des $\beta$-agonistes au niveau adipocytaire concerne leur interaction avec les effets de l'insuline. Des études in vitro sur l'adipocyte isolé ont montré que les catécholamines peuvent, par stimulation des $\beta$ récepteurs inhiber le transport du glucose stimulé par l'insuline (Smith et al., 1984 ; Kashiwagi et al., 1983). Cet effet a été récemment observé après traitement chronique au clenbutérol chez la souris (Orcutt et al., 1986). Le $\beta$-agoniste réduit l'effet lipogénique de l'insuline; cette action est due à une réduction de la sensibilité des adipocytes à l'insuline. Des études détaillées réalisées sur l'adipocyte de l'homme ou du rat ont montré que cet effet est dû, au niveau de l'adipocyte, à une inhibition de la translocation des transporteurs glucose (stimulée par l'insuline) du pool intracellulaire vers la membrane plasmique et à une réduction de l'activité intrinsèque de transport de ces transporteurs (Smith et al., 1984 ; Kashiwagi et al., 1983). De plus, les travaux récents ont également montré que la stimulation des $\beta$-récepteurs provoque une réduction de la liaison de l'insuline à ses récepteurs adipocytaires (Pessin et al., 1983 ; Lonnröth et al., 1985). II faut donc remarquer qu'au niveau de l'adipocyte les $\beta$-agonistes peuvent provoquer une insulino-résistance en provoquant de nettes perturbations tant au niveau récepteur que post-récepteur (Arsenis et Livingston, 1986). Cet effet remarquable 
vient renforcer les actions décrites précédemment ; il faut remarquer qu'il n'intéresse pas les récepteurs insuline de tous les tissus comme nous le verrons ultérieurement. On peut s'interroger sur l'importance d'un tel effet chez le ruminant car certains travaux (Vasilatos et al., 1983) ont suggéré que l'insuline a des effets réduits sur le métabolisme du glucose du tissu adipeux de bovin in vitro. Des travaux plus récents, en contradiction avec les premiers, ont montré que l'adipocyte de bovin possède des récepteurs insuline qui diffèrent peu (en nombre et propriétés) des récepteurs insuline de l'adipocyte de rat. De plus, dans des conditions expérimentales bien contrôlées, ces adipocytes répondent à des doses physiologiques d'insuline (Vernon et al., 1985 ; Etherton et Evock, 1986).

$\mathrm{Au}$ vu des données actuellement disponibles, le clenbutérol et le cimatérol semblent différer, par leur action sur le muscle des autres familles de $\beta$-agonistes récemment synthétisés $(L Y-79,730$, LY-79,771, divers $B R L$ de la firme Beecham Pharmaceuticals). Ces composés doués de propriétés lipomobilisatrices ont été décrits comme possédant un " effet antiobésité » marqué chez le rat et les rongeurs génétiquement obèses (souris ob/ob, rat fa/fa). Ces agents pharmacologiques entrainent une nette réduction des dépôts adipeux sans avoir d'action marquée sur la masse maigre (Shaw et al., 1981 ; Holloway et al., 1985 ; Ashwell et al., 1987 ; Arch et al., 1984a ; 1984b). De plus, contrairement aux autres $\beta$ agonistes ils favoriseraient l'effet de l'insuline sur l'adipocyte (Young et al., 1984 ; 1985) et auraient une certaine action antidiabétique (Caroll et al., 1985). Leur action s'expliquerait par un effet sur la mobilisation lipidique (au niveau de l'adipocyte blanc et brun) mais aussi par une action thermogénique puissante au niveau de l'adipocyte brun.

La stimulation du récepteur $\beta$-adrénergique de l'adipocyte brun (par la noradrénaline ou des $\beta$-agonistes) conduit à une forte lipolyse et à une nette activation de l'activité thermogénique. La mitochondrie de l'adipocyte brun contient une protéine spécifique appelée "protéine découplante " ou thermogénine qui joue un rôle essentiel dans la genèse de l'effet thermogénique (Ricquier et Bouillaud, 1986). Les acides gras libres libérés au cours de la lipolyse sont capables d'agir directement sur la protéine découplante et de conduire à son activation (découplage de la mitochondrie et amplification de la production de chaleur). La stimulation chronique des $\beta$-récepteurs provoque un net accroissement des taux de protéine découplante ; elle induit la transcription du gène de la protéine découplante conduisant ainsi à une néosynthèse de la protéine qui va s'insérer dans la membrane interne des mitochondries du tissu adipeux brun (Ricquier et al., 1986). La stimulation $\beta$-adrénergique chronique de l'activité du tissu adipeux brun et de la thermogenèse provoque un accroissement des dépenses énergétiques associé à une réduction du tissu adipeux blanc. Ce type d'action explique en grande partie l'effet antiobésité de cette famille de $\beta$-agonistes ; il faut souligner que ces réponses n'ont été clairement observées que chez le rongeur, elles n'ont pas été décrites chez l'homme et chez diverses espèces ne possédant pas ou ayant peu de tissu adipeux brun à l'âge adulte.

Dans le cas du rat, qui possède un tissu adipeux brun bien développé à l'âge adulte, le clenbutérol exerce un effet thermogénique équivalent à celui produit par un $\beta 1$-agoniste tel que le prénaltérol. Chez cette espèce l'effet lipomobilisateur et 
thermogénique peut expliquer en partie la réduction de la masse grasse, il est à remarquer qu'il n'empêche pas l'effet du clenbutérol sur l'accrétion musculaire (Stock et Rothwell, 1986).

II ne semble pas que les petits rongeurs de laboratoire (rat, souris) puissent constituer les meilleurs modèles expérimentaux pour l'étude des mécanismes d'action des $\beta 2$-agonistes à effet « répartiteur " du fait de l'existence d'un certain niveau de dissipation énergétique assuré par le tissu adipeux brun. Chez les espèces $n$ 'ayant pas ou peu de tissu adipeux brun les facteurs de répartition permettent probablement une meilleure utilisation de l'énergie disponible en l'orientant vers une augmentation de l'accrétion des protéines des muscles. II reste à établir l'existence et la contribution éventuelle du tissu adipeux brun chez les espèces adultes utilisées en production animale avant d'envisager tout impact éventuel des $\beta 2$-agonistes sur le tissu adipeux brun. Le tissu adipeux brun existe chez le fœtus et les bovins et ovins nouveau-nés (Fain et al., 1984 ; Casteilla et al., 1987).

\section{d) B2-agonistes et synthèse protéique.}

L'un des effets les plus remarquables de ces nouveaux $\beta 2$-agonistes à effet " répartiteur » concerne leur effet sur l'accrétion des protéines des muscles squelettiques. En dehors d'une action à médiation centrale (hormone de croissance) cet effet peut s'expliquer par l'action conjointe d'un impact vasculaire (vasodilatation permettant une meilleure perfusion et oxygénation des muscles par un net accroissement du flux sanguin (Beerman et al., 1986b ; Rothwell et al., 1987 ; Eisemann et al., 1986) et d'une action plus directe par l'intermédiaire des $\beta 2$ récepteurs musculaires (Williams et al., 1984 ; Böcklen et al., 1986) (fig. 2).

Des travaux avaient attiré l'attention sur le fait que l'administration chronique d'isoprotérénol, agoniste $\beta$-adrénergique mixte, provoque une hypertrophie du muscle cardiaque (Stanton et al., 1969 ; Gordon, 1972). Cet effet a été récemment décrit après administration de clenbutérol (Rothwell et al., 1987). Chez le rat, les effets précoces des $\beta$-agonistes semblent porter sur un accroissement de l'incorporation des aminoacides (identifiés par radiomarquage) dans les protéines totales du cœur et du muscle ; cet effet sur l'incorporation s'estompe au bout de quelques jours (Deshaies et al., 1981). L'hypertrophie des muscles striés est variable selon le type musculaire considéré ; le muscle tibial (muscle intermédiaire) est plus sensible à cet effet que le muscle soleus (muscle lent). Ce type d'effet est encore mal expliqué. Le clenbutérol stimule également la synthèse protéique musculaire in vivo chez le rat (Emery et al., 1984).

L'approche des mécanismes d'action a été tentée à l'issue d'études in vitro sur des muscles isolés ou sur des préparations musculaires perfusées. II faut remarquer que cette situation expérimentale ne permet probablement pas d'établir de bonnes corrélations avec les observations réalisées in vivo; elle permet cependant de tester l'éventualité d'un effet direct des $\beta$-agonistes sur le muscle. Des travaux assez discordants ont été rapportés sur les effets des catécholamines sur le muscle strié (Nutting, 1982). Selon certains auteurs, les catécholamines inhibent la synthèse protéique, la captation d'amino-acides et des oses tout en stimulant la glycogénolyse et l'oxydation des amino-acides ramifiés. Cependant d'autres n'ont pas noté d'effets nets des amines sur la synthèse protéique ( $L i$ et 


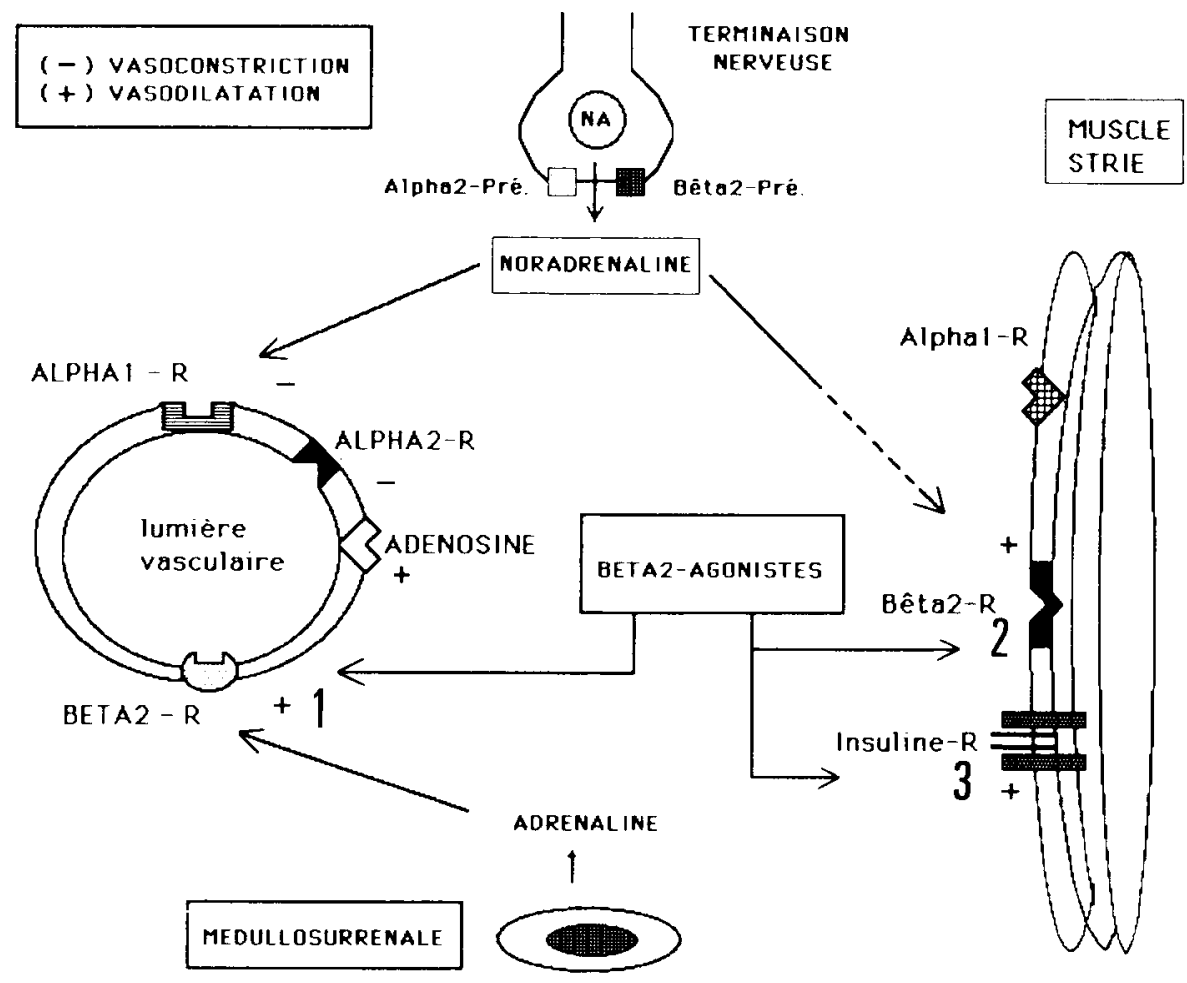

FIG. 2. - Schéma des points d'impact majeurs des bêta2-agonistes sur le système vasculaire et le muscle strié.

Les commentaires correspondent à ceux de la figure 1 ; le récepteur insuline a été représenté afin de suggérer les interactions catécholamines/insuline dans le muscle. Les $\beta 2$-agonistes peuvent exercer trois actions essentielles figurées sur le schéma : 1) action vasodilatatrice par interaction avec les $\beta 2$-récepteurs vasculaires, 2) stimulation des $\beta 2$-récepteurs de la fibre musculaire et 3 ) induction d'un accroissement de la liaison insuline sur la fibre musculaire par un mécanisme encore mal identifié (Webster et al., 1986a et 1986b).

Jefferson, 1977 ; Reeds et al., 1986). Les agonistes adrénergiques semblent diminuer la libération d'alanine et de glutamine par le muscle isolé (Garber et al., 1976). Ce type d'effet a été récemment rapporté sur des myoblastes de souris en culture sur lesquels le cimatérol réduirait la dégradation protéique (Forsberg et Merrill, 1986). Bien que des approches plus convaincantes soient encore nécessaires, on peut penser que dans une situation où le taux de synthèse protéique reste constant, l'inhibition du catabolisme protéique peut rendre compte de l'hypertrophie musculaire observée avec les $\beta 2$-agonistes.

II faut souligner que des injections répétées d'isoprénaline entraînent également une augmentation des enzymes oxydatives de la mitochondrie du muscle (Harri et Valtola, 1975) ; effets qui rappellent par certains points l'adaptation musculaire induite par l'entraînement physique. II semble que cette adaptation soit due, en grande partie, à l'activation du système sympathique contemporaine de 
l'exercice. Les $\beta$-bloquants réduisent les effets de l'entraînement physique (Harri, 1980 ; Ji et al., 1986) ; les récepteurs $\beta 2$-adrénergiques joueraient un rôle essentiel dans l'adaptation enzymatique induite dans le muscle au cours de l'exercice physique (Williams et al., 1984). On peut s'interroger sur les effets engendrés par l'administration chronique d'un $\beta$-agoniste ; rappellent-ils par certains points ceux engendrés par une activité physique chronique?

Une étude plus précise du problème doit tenir compte des différences existant entre les divers types de muscles squelettiques et les types de fibres musculaires. Le muscle squelettique est hétérogène et les effets des agents pharmacologiques peuvent varier selon la composition en fibres du muscle considéré. Le rapport entre le nombre de fibres de type I (à contraction lente, oxydatives) et le nombre de fibres de type II (à contraction rapide, oxydatives et glycolytiques) ne paraît pas être modifié par un traitement chronique au cimatérol chez l'agneau. Selon les auteurs, l'accroissement de la masse musculaire semble être dû à l'hypertrophie des deux types de fibres (Beerman et al., 1985a) ou des seules fibres de type II, les fibres de type I restant inchangées (Kim et al., 1986).

En dehors d'un effet direct des $\beta 2$-agonistes sur la fibre musculaire on doit également envisager des effets indirects, plus complexes, médiés par l'insuline. L'adrénaline peut induire un accroissement de la liaison de l'insuline aux récepteurs insuliniques musculaires ; cet effet peut être bloqué par le propranolol, un antagoniste $\beta$-adrénergique non spécifique. Ce phénomène ne nécessite pas l'intégrité de la fibre musculaire car il est également observé sur des préparations membranaires brutes. Cette action a l'air d'être étroitement dépendante du $\beta$-récepteur (Webster et al., 1986a). Ce type d'effet s'observe également pendant un exercice aigu (Webster et al., 1986b) ou à l'issue d'un entraînement chronique chez le rat (Bonen et al., 1986), deux situations physiologiques contemporaines d'une activation du système nerveux sympathique. Cet accroissement de la liaison insuline permet d'expliquer la meilleure efficience de l'insuline sur le muscle (recrutement et activation du transport glucose et de l'acide $\alpha$-aminoisobutyrique) décrite après un exercice physique (Zorzano et al., 1985 ; 1986). Il paraît raisonnable d'envisager que la stimulation chronique des $\beta$-récepteurs musculaires est susceptible d'induire, elle aussi, un accroissement de la sensibilité du muscle strié à l'insuline ; I'hormone pourrait alors voir renforcer ses effets trophiques sur le muscle. Cet effet, spécifique à certains types de muscles striés, ne s'observe pas dans le foie (Bonen et al., 1986) et le tissu adipeux et pourrait peut-être s'expliquer par la différence de structure des récepteurs insuline des différents tissus (Buran et al., 1986 ; James et al., 1986).

\section{Conclusions.}

\section{1) Aspects zootechniques.}

Tous les essais concourent à mettre en lumière la diminution des dépôts gras et l'accroissement musculaire chez les ovins et bovins traités au clenbutérol et cimatérol. Les données sur les jeunes ou en phase d'allaitement vont dans le même sens. 
Leur emploi sous la forme "d'additifs alimentaires " est pratique pour les sujets à l'engraissement à condition de ne pas utiliser de trop fortes doses: $0,125 \mathrm{mg} / \mathrm{kg}$ vif/jour de cimatérol chez les ovins selon Hanrahan et al. (1986), $50 \mathrm{mg} /$ tête/jour chez les bovins selon Quirke et al. (1986).

Chez les animaux sous la mère ou à l'herbe, Thornton et al. (1985) suggèrent l'utilisation d'implants, des injections sous-cutanées répétées n'ayant entraîné aucune réaction nuisible au cours d'essais de longue durée.

Un nombre important de points d'interrogation subsiste sur l'efficacité des traitements dans les conditions d'élevage en France, notamment chez les ovins qui sont abattus plus légers et moins gras.

L'incidence de l'amaigrissement des muscles sur les qualités organoleptiques des viandes, la recherche d'une rémanence des produits utilisés et des conséquences éventuelles pour le consommateur restent à définir. Enfin la démonstration de l'absence d'effets indésirables ou latéraux touchant la circulation, le tractus digestif ou les glandes endocrines des animaux traités revêt aussi une grande importance.

\section{2) Mécanismes d'action.}

A la diversité des points d'impact potentiels de ces nouveaux composés doués d'un pouvoir répartiteur s'ajoute la rareté des travaux fondamentaux chez les animaux domestiques présentant un intérêt économique en production animale.

Chacun des volets évoqués requiert des études approfondies qui font grandement défaut pour l'instant. A côté des aspects pharmacocinétiques et toxicologiques qui n'ont pas été évoqués ici il conviendrait:

- de mieux préciser l'impact éventuel de ces composés sur le système nerveux central et sur l'axe hypothalamo-hypohysaire :

- de déterminer les effets aigus et chroniques des traitements aux $\beta$-agonistes sur la sécrétion d'insuline et les taux de catécholamines plasmatiques ;

- de caractériser les récepteurs $\beta$-adrénergiques de l'adipocyte blanc (et brun) et de définir l'interaction de ces composés avec le tissu adipeux des diverses espèces utilisées en production animale. II paraît essentiel de clarifier les effets lipolytiques (" in vivo " et " in vitro »), les actions antilipogéniques et les interactions $\beta$ récepteurs/récepteurs insuline au niveau de l'adipocyte ;

- de préciser l'impact vasculaire et musculaire de ces composés " répartiteurs" afin de cerner les mécanismes d'action qui restent encore très confus dans ce domaine. II paraît essentiel de définir l'état endocrino-métabolique du muscle squelettique en début et en fin de traitement aux $\beta 2$-agonistes " répartiteurs ». II serait intéressant d'explorer :

- l'évolution du flux sanguin et de la consommation d'oxygène,

- les propriétés des récepteurs $\beta 2$-adrénergiques et insuliniques du sarcolemme des muscles les plus réactifs à cette famille de composés,

- les effets de l'insuline et leur évolution,

- les capacités de modulation de la liaison et des effets insuline par les $\beta 2$ agonistes. 
En guise de conclusion, on doit donc souligner qu'il y a encore beaucoup de réponses à donner à ces questions avant que l'utilisation pratique de ces substances à grande échelle puisse être raisonnablement envisagée.

3emes Journées sur la Nutrition et l'Alimentation des Herbivores, I.N.R.A., Paris, 26 et 27 mars 1987.

\section{Références}

AHREN B., LUNDQUIST I., 1981. Effects of selective and non-selective $\beta$-adrenergic agents on insulin secretion in vivo. Eur. J. Pharmac., 71, 93-104.

ARCH J. R. S., AINSWORTH A. T., CAWTHORNE M. A., PIERCY V., SENNIT M. V., THODY V. E., WILSON C., WILSON S., 1984a. Atypical $\beta$-adrenoceptor on brown adipocytes as target for antiobesity drugs. Nature, 309, 163-165.

ARCH J. R. S., AINSWORTH A. T., ELLIS R. D. M., PIERCY V., THODY V. E., THURLBY P. L., WILSON C., WILSON S., YOUNG P., 1984b. Treatment of obesity with thermogenic $\beta$-adrenoceptor agonists : studies on BRL-26830. A in rodents. Int. J. Obesity, 8, Suppl. 1, 111.

ARIENS E. J., SIMONIS A. M., 1983. Physiological and pharmacological aspects of adrenergic receptor classification. Biochem. Pharmacol, 32, 1539-1545.

ARSENIS G., LIVINGSTON J. N., 1986. Isoproterenol reduces insulin stimulation of hexose uptake by rat adipocytes via postinsulin binding alteration. Endocrinologv, 119, 50-57.

ASHWELL M., STIRLING D., FREEMAN S., HOLLOWAY B. R., 1987. Immunological, histological and biochemical assessment of brown adipose tissue activity in neonatal, control and $\beta$ stimulant-treated adult. Int. J. Obesity, 11, 357-365.

BAKER P. K., DALRYMPLE R. H., INGLE D. L., RICKS C. A., 1984. Use of a $\beta$-adrenergic agonist to alter muscle and fat deposition in lambs. J. anim. Sci, 59, 1256-1261.

BEERMAN D. H., FISHELL V. K., HOGUE D. E., RICKS C. A., DALRYMPLE R. H., 1985a. Effects of the repartitioning agent, cimaterol (CL 263780 ) on skeletal muscle fiber type and fiber hypertrophy in lambs. J. anim. Sci., 61, Suppl. 1, Abstr. 116.

BEERMAN D. H., BUTLER W. R., HOGUE D. E., DALRYMPLE R. H., RICKS C. A., $1985 \mathrm{~b}$. Plasma metabolic hormone, glucose and free fatty acid concentrations in lambs fed the repartitioning agent, cimaterol (CL 263 780). J. anim., Sci., 61, Suppl. 1, Abstr. 118.

BEERMAN D. H., HOGUE D. E., FISHELL V. K., DALRYMPLE R. H., RICKS C. A., 1986a. Effects of cimaterol and fishmeal on performance carcass characteristics and skeletal muscle growth in lambs. J. anim. Sci., 62, 370-380.

BEERMAN D. H., BULERW R., FISHELL V. K., BERGMAN E. N., Mc CANN J. P., 1986b. Preliminary observations on the effects of cimaterol on heart rate, blood flow, plasma insulin concentration and net glucose uptake in the hind quarters of growing lambs. J. anim. Sci., 63, Suppl. 1, Abstr. 160.

BEERMAN D. H., REEDS P. J., HOWELL F. D., KYLE D., 1986c. Cimaterol elicits rapid physiological responses in growing lambs wholly nourished by intragastric infusion. $J$. anim. Sci., 63, Suppl. 1, Abstr. 195.

BERNE R. S., NOVAKOFSKI J., BECHTEL P. J., 1985. Effects of the $\beta$-agonist clenbuterol on body and tissue weights in four strain of rats. J. anim. Sci., 61, Suppl. 1, Abstr. 119.

BÖCKLEN E., FLAD S., MÜLLER E., VON FABER H., 1986. Comparative determination of $\beta$-adrenergic receptors in muscle, heart and back fat of pietrain and large white pigs. Anim. Prod., 43, 335-340.

BONEN A., CLUNE P. A., TAN M. H., 1986. Chronic exercise increases insulin binding in muscles but not liver. Am. J. Physiol., 251, E196-E203.

BLOOM S. R., EDWARDS A. V., 1985. The role of sympathetic system in the control of insulin release in response to hyperglycemia in conscious calves. J. Physiol., 362, 311-317. 
BLUET-PAJOT M. T., SCHAUB C., MOUNIER F., SEgALEN A., DUHAULT J., KORdON C., 1980. Monoaminergic regulation of growth hormone in the rat. J. Endocr., 86, 387-396.

BLUET-PAJOT M. T., DURAND D., MOUNIER F., SCHAUB C., KORDON C., 1982. Interaction of $\beta$-adrenergic agonists and antagonists with the stimulation of growth hormone release induced by clonidine or by morphine in the rat. J. Endocr., 94, 327-331.

BURAN C. F., TREUTELAAR M. K., BLOCK N. E., BUSE M. G., 1986. Structural differences between liver and muscle-derived insulin receptors in rat. J. biol. Chem., 261, 14361-14364.

CAROLL M. J., LISTER C. A., SENNITT M. V., STEWART-LONG N., CAWTHORNE M. A., 1985. Improved glycemic control in $\mathrm{C} 57 \mathrm{BI} / \mathrm{KsJ}(\mathrm{db} / \mathrm{db})$ mice after treatment with the thermogenic $\beta$-adrenoceptor agonist, BRL-26830. Diabetes, 34, 1198-1204.

CASTEILLA L., FOREST C., ROBELIN J., RICQUIER D., LOMBET A., AILHAUD G., 1987. Characterization of the mitochondrial uncoupling protein in bovine fœtus and new-born calf. Disappearance in lamb during aging. Amer. J. Physiol. (in press).

COHEN H. L., WILEY K. S., BEMIS K. G., 1982. Analysis of the beta 1-and beta 2-adrenoceptor interactions of the partial agonist, clenbuterol (NAB 365) in the rat jugular vein and atria. Naunyn-Schmied. Arch. Pharmacol., 320, 145-151.

DAHLÖF C., 1981. Studies of $\beta$-adrenoceptor mediated facilitation of sympathetic neurotransmission. Acta physiol. scand., 500, 1-147.

DAHLÖF C., HEDBERG, NERME V., 1986. Evidence for prejunctionally located $\beta 2$-adrenoceptors in the cat spleen. Naunyn Schmied. Arch. Pharmacol., 333, 362-367.

DALRYMPLE R. H., RICKS C. A., BAKER P. K., PENSACK J. M., GINGHER P. E., INGLE D. L., 1984. Use of the $\beta$-agonist clenbuterol to alter carcass composition in poultry. Poultry Sci., 63. 2376.

DESHAIES Y., WILLEMOT J., LEBLANC J., 1981. Protein synthesis, amino acid uptake and pools during isoproterenol-induced hypertrophy of the rat heart and tibialis muscle. Can. J. Physiol. Pharmacol., 59, 113-121.

DOOLEY D. J., HAUSER K. L., BITTIGER H., 1983. Differential decrease of the central betáadrenergic receptor in the rat after subchronic infusion of desipramine and clenbuterol. Neurochem. Int., 5, 333-338.

DUQUETTE P. F., MUIR L. A., 1985. Effect of the beta-adrenergic agonists isoproterenol, clenbuterol, L-640,033 and BRL-35135 on lipolysis and lipogenesis in rat adipose tissue in vitro. J. anim. Sci., 61, Suppl. 1, Abstr. 141.

EISEMANN J. H., HUNTINGTON G. B., FERELL C. L., 1986. Clenbuterol increases hind limb blood flow and oxygen uptake in steers. J. anim. Sci, 63, Suppl. 1, Abstr. 191.

EMERY P. W., ROTHWELL N. S., STOCK M. J., WINTER P. O., 1984. Chronic effects of $\beta 2$-adrenergic agonists on body composition and protein synthesis in the rat. Biosci. Rep., 4, 83-91.

ETHERTON T. D., EVOCK C. M., 1986. Stimulation of lipogenesis in bovine adipose tissue by insulin and insulin-like growth factor. J. anim. Sci, 62, 357-362.

FAIN J. N., MOHELL N., WALLACE M. A., MILLS I., 1984. Metabolic effects of $\beta-, \alpha 1-$ and $\alpha 2$-adrenoceptor activation on brown adipocytes isolated from the perirenal adipose tissue of fetal lambs. Metabolism, 33, 289-294.

FORSBERG N. E., MERRIL G., 1986. Effect of cimaterol on protein synthesis and degradation in monolayer cultures of rat and mouse myoblasts. J. anim. Sci., 63, Suppl. 1, Abstr. 151.

GARBER A. J., KARL I. E., KIPNIS D. M., 1976. Alanine and glutamine synthesis and release from skeletal muscle. J. biol. Chem., 251, 851-857.

GORDON A. L., 1972. Isoproterenol-induced cardiomegaly: assessment of myocardial protein content, actomyosin, ATPase and heart rate. J. mol. cell. Cardiol., 4, 543-557.

HALLBERG H., ALMGREN D., SVENSSON T. H., 1981. Increased brain serotoninergic and noradrenergic activity after repeated systemic administration of the beta 2-adrenoceptor agonist salbutamol, a putative antidepressant drug. Psychopharmacology, 73, 201-204.

HARRI M. N. E., 1980. Physical training under the influence of beta-blockade in rats. III. Effect on muscle metabolism. Eur. J. app/. Physiol, 45, 25-31.

HARRI M. N. E., VALTOLA J., 1975. Comparison of the effect of physical exercise, cold acclimatation and repeated injection of isoprenaline on rat muscle enzymes. Acta physiol. scand., 95, 391-399. 
HOLLOWAY B. R., STRIBLING D., FREEMAN S., JAMIESON L., 1985. The thermogenic role of adipose tissue in the dog. Int. J. Obesity, 9, 423-432.

HANRAHAN J. P., QUIRKE J. F., BOMANN W., ALLEN P., Mc EWAN J. C., FITZSIMONS J. M., KOTZIAN J., ROCHE J. F., 1986. $\beta$-agonists and their effects on growth and carcass quality, 125-138. In HARESIGN W., COLE D. J. A., Recent advances in animal nutrition. Butterworths, London.

INGLE D. L., DALRYMPLE R. H., 1986. Les $\beta$-agonistes en tant que facteurs de répartition des lipides et des protéines au niveau cellulaire. Résultats américains AFZ Biotechnologie et Zootechnie. AFZ. Paris. 13-11-1986.

JAMES D. E., ZORZANO A., BÖNI-SCHNETZLER M., NEMENOFF R. A., POWERS A., PILCH P. F., RUDERMAN N. B., 1986. Intrinsic differences of insulin receptor kinase activity in red and white muscle. J. biol. Chem., 258, 13685-13692.

JI L. L., LENNON D. L. F., KOCHAN R. G., NAGLE F. J., LARDY H. A., 1986. Enzymatic adaptation to physical training under beta-blockade in the rat. Evidence of a beta 2-adrenergic mechanism in skeletal muscle. J. clin. Invest., 78, 771-778.

JONES R. W., EASTER R. A., Mc KEITH F. K., DALRYMPLE R. H., MADDOCK H. M., BECHTEL P. J., 1985. Effect of the $\beta$-adrenergic agonist cimaterol ( $C L 263,780)$ on the growth and carcass characteristics of finishing swine. J. anim. Sci., 61, 905-913.

KASHIWAGI A., HUECKSTEADT T. P., FOLEY J. E., 1983. The regulation of glucose transport by CAMP stimulators by different mechanisms in rat and human adipocytes. J. biol. Chem., 258, 13685-13692.

KAZANIETZ M. G., GUTKIND J. S., ENERO A. E., 1986 . Interaction between $\beta 2$ - and $\alpha 2$-adrenoceptor responses in the vascular system : effect of clenbuterol. Eur. J. Pharmacol., 130, 119124.

KENDALL M. J., 1981. Are selective beta-adrenoceptor blocking drugs and advantage ? J. roy. Coll. Phys., 15, 33-40.

KIM Y. S., LEE Y. B., ASHMORE C. R., DALRYMPLE R. H., 1986. Effect of the repartitionning agent, cimaterol ( $C L 263,780$ ) on growth, carcass characteristics and skeletal muscle cellularity of lambs. J. anim. Sci, 63, Suppl. 1, Abstr. 148.

LAFONTAN M., 1986. Physiologie et pharmacologie de la mobilisation des lipides : aspects actuels et futurs. Cah. Nutr. Diét., XXI, 1, 19-46.

LAFONTAN M., 1985. Fat cell adrenoceptors : inter- and intraspecific differences and hormone regulation. Int. J. Obesity, 9, Suppl. 1, 117-127.

LAGER I., ATTVALL S., ERIKSSON B. M., VON SCHENK H., SMITH U., 1986. Studies on the insulin-antagonistic effect of catecholamines in normal man. Evidence for the importance of 32-receptors. Diabetologia, 29, 409-416.

LANDS A. M., ARNOLD A., Mc AULIFF J. P., LUDUENA F. P., BROWN T. G. Jr., 1967. Differentiation of receptor systems activated by sympathomimetic amines. Nature, 214, 597-598.

LANGER S. Z., 1980. Presynaptic regulation of the release of catecholamines. Pharmacol. Rev., 32, 337-363.

LECRUBIER Y., PUECH A. J., JOUVENT R., SIMON P., WIDLOCHER D., 1980. A $\beta$-adrenergic stimulant (salbutamol) versus clomipramine in depression-a controlled study. Br. J. Psychiatry, 136, 354-358.

LIANG B. T., MOLINOFF P. B., 1986. Beta adrenergic receptor subtypes in the atria. Evidence for close coupling of beta 1 - and beta 2 -adrenergic receptors to adenylate cyclase. J. Pharmac. exper. Ther., 238, 886-892.

LI J. B., JEFFERSON L. S., 1977. Effects of isoproterenol on amino-acid levels and protein turnover in skeletal muscle. Amer. J. Physiol, 232, E 243.

LÖNNROTH P., WESSLAU C., STENSTRÖM G., TISELL L. E., STMITH U., 1985. Reduced insulin binding to human fat cells following beta-adrenergic stimulation-experimental evidence and studies in patients with a phaeochromocytoma. Diabetologia, 28, 901-906.

LOUBATIERES A., MARIANI M. M., SOREL G., SAVI L., 1971. The action of $\beta$-adrenergic blocking and stimulating agents on insulin secretion. Characterization of the type of $\beta$ receptor. Diabetologia, 7, 127-132.

LUNDQUIST I., ERICSON L. E., 1978. Beta-adrenergic insulin release and adrenergic innervation of mouse pancreatic islets. Cell Tissue Res., 193, 73-85. 
MAJEWSKI H., 1983. Modulation of noradrenaline release through activation of presynaptic $\beta$-adrenoceptors. J. autonom. Pharmacol., 3, 47-60.

MALTIN C. A., DELDAY M. I., REEDS P. J., 1986. The effect of a growth promoting drug clenbuterol on fibre frequency and area in hindlimb muscle from young male rats. Biosci. Rep., 6, 293-299.

MERSMANN H. J., 1984a. Adrenergic control of lipolysis in swine adipose tissue. Comp. Biochem. Physiol, 77 C, 43-53.

MERSMANN H. J., 1984b. Specificity of $\beta$-adrenergic control of lipolysis in swine adipose tissue. Comp. Biochem. Physiol., 77 C. 39-42.

MILLER M. F., GARCIA D. K., COLEMAN M. E., EKEREN P. A., SMITH S. B., $1986 . \quad$ Nonesterified and glyceride-fatty acid synthesis in bovine adipose tissue from heifers fed clenbuterol. $J$. anim. Sci., 63, Suppl. 1, Abstr. 187.

MOGILNICKA E., NIELSEN M., 1986. Repeated treatment with clenbuterol produces desensitization of rat brain $\beta$-and $\alpha 2$-adrenoceptors without changes of $\alpha 1$-adrenoceptors. Eur. J. Pharmacol., 121, 107-111.

MUKHERJEE A., HAGHANI Z., BRADY J., BUSH L., McBRIDE W., BUJA L. M., WILLERSON J. T., 1983. Differences in myocardial $\alpha$ and $\beta$-adrenergic receptor mumbers in different species. Am. J. Physiol., 245, H957-H961.

NUTTING D. F., 1982. Anabolic effects of catecholamines in diaphragm muscle from hypophysectomized rats. Endocrinology, 110, 307-317.

O'DONNELL J. M., FRAZER A., 1985. Effect of clenbuterol and antidepressant drugs on beta adrenergic receptor/N-protein coupling in the cerebral cortex of the rat. J. Pharmac. exper. Ther., 234, 30-36.

ORCUTT A. L., CLINE T. R., MILLS S. E., 1986. Influence of beta-adrenergic agonists on sensitivity of mouse adipocytes to insulin. J. anim. Sci., 63, Suppl. 1, Abstr. 174.

PERKINS S. N., EVANS W. S., THORNER M. O., GIBBS D. M., CRONIN M. J., $1985 . \quad \beta$-adrenergic binding and secretory responses of the anterior pituitary. Endocrinology, 117, 1818-1825.

PESSIN J. E., GITOMER W., YOSHITOMO O., OPPENHEIMER C. L., CZECH M., 1983. $\beta$-adrenergic regulation of insulin and epidermal growth factor receptors in rat adipocytes. $J$. biol. Chem., 258, 7386-7394.

QUiRKE J. F., ALLEN P., MOLONEY A., MAUREL U., HANRAHAN J. P., SHEEMAN W., ROCHE J. F., 1986. Effets du cimaterol, bêta-agoniste, sur les taurillons frisons en finition. Biotechnologie et Zootechnie. Réunion AFZ. Paris (13-11-1986).

RAND M. J., MAJEWSKI H., 1984. Adrenaline mediates a positive feedback loop in noradrenergic transmission : its possible role in development of hypertension. Clin. exper. Hypert-Theory Practice, 347-370.

REEDS P. J., HAY S. M., DORWOOD P. M., PALMER R. M., 1986. Stimulation of muscle growth by clenbuterol : lack of effect on muscle protein biosynthesis. Br. J. Nutr., 56, 249258.

RICKS C. A., DALRYMPLE R. H., BAKER P. K., INGLE D. L., 1984. Use of $\beta$-agonists to alter fat and muscle deposition in steers. J. anim. Sci., 59, 1247-1255.

RICQUIER D., BOUILLAUD $F_{1}, 1986$. The brown adipose tissue mitochondrial uncoupling protein. 86-104. In TRAYHURN P., NICHOLLS D. G., Brown adipose tissue, Edward Arnold, London.

RICQUIER D., BOUILLAUD F., TOUMELIN P., BAZIN R., ARCH J., PENICAUD L., 1986. Expression of uncoupling protein mRNA in thermogenic or weakly thermogenic brown adipose tissue. Evidence for a rapid $\beta$-adrenoceptor-mediated and transcriptionally regulated step during activation of thermogenesis. J. biol. Chem., 261, 13905-13910.

ROTHWELL N. J., STOCK M. J., SUDERA D. K., 1987. Changes in tissue blood flow and $\beta$-receptor density of skeletal muscle in rats treated with the $\beta 2$-adrenoceptor agonist clenbuterol. Br. J. Pharmac., 90, 601-607.

SHAW W. N., SCHMIEGEL K. K., YEN T. T., TOOMEY R. E., MEYERS D. B., MILLS J., 1981. LY 79771 : a novel compound for weight control. Life Sci, 29, 2091-2101.

SIMON P., LECRUBIER Y., JOUVENT R., PUECH A., WIDLOCHER D., 1984. Beta-receptor stimulation in the treatment of depression. Adv. Biochem. Psychopharmacol., 39, 293-299.

SMITH V., KURODA M., SIMPSON I. A., 1984. Counter-regulation of insulin-stimulated glucose transport by catecholamines in the isolated rat adipose cell. J. biol. Chem., 259, 8758-8763. 
STANTON H. C., BRENNER G., MAYFIELD E. D., 1969. Studies on isoproterenol-induced cardiomegaly in rats. Am. Heart. J., $7,72.80$.

STOCK M. J., ROTHWELL N. J., 1986. Effects of $\beta$-adrenergic agonists on metabolism and body composition, 249-257. In BUTTERY P. J., HAYNES N. B., LINDSAY D. B. Growth and manipulation of animal growth. Butterworths, London.

THORNTON R. F., TUME R. K., PAYNE G., LARSEN T. W., JOHNSON G. W., HOHENHAUS M. A., 1985. The influence of the beta 2-adrenergic agonist, clenbuterol on lipid metabolism and carcass composition of sheep. Proc. N. Z. Soc. anim. Prod., 45, 97-101.

TRENKLE A., 1981. Endocrine regulation of energy metabolism in ruminants. Fed. Proc., 40, 25362541.

TUOMISTO J., MÄNNISTO P., 1985. Neurotransmitter regulation of anterior pituitary hormones. Pharmacol. Rev., 37, 249-332.

VASILATOS R., ETHERTON T. D., WANGSNESS P. J., 1983. Preparation of isolated bovine adipocytes : validation of use for studies characterizing insulin sensitivity and binding. Endocrinology, 112, 1667-1673.

VERNON R. G., FINLEY E., TAYLOR E., FLINT D. J., 1985. Insulin binding and action on bovine adipocytes. Endocrinology, 116, 1195-1199.

WALDECK B., WIDMARK B., 1985. Steric aspects of agonism and antagonism at $\beta$-adrenoceptors : experiments with the enantiomers of clenbuterol. Acta pharmacol. toxicol., 56, 221-227.

WEBSTER B. A., VIGNA S. R., PAQUETTE T., KOERKER D. J., 1986a. $\beta$-adrenergic modulation of insulin binding in skeletal muscle. Am. J. Physiol., 250, E198-E204.

WEBSTER B. A., VIGNA S. R., PAQUETTE T., 1986b. Acute exercise, epinephrine, and diabetes enhance insulin binding in skeletal muscle. Am. J. Physiol., 250, E186-E197.

WILLIAMS P. E. V., POGLIANI L., INNES G. M., 1986. The effect of a $\beta$-agonist (clenbuterol) on the heart rates, nitrogen balance and some carcass characteristics of veal calves. Livest. Prod. Sci., 15, 289-293.

WILLIAMS R. S., CARON M. G., DANIEL K., 1984. Skeletal muscle $\beta$-adrenergic receptors : variations due to fiber type and training. Am. J. Physiol, 246, E160-E167.

WILSON C., WILSON S., PIERCY V., SENNITT M. V., ARCH J. R. S., 1984. The rat lipolytic $\beta$-adrenoceptor: studies using a novel $\beta$-adrenoceptor agonist. Eur. J. Pharmacol., 100, 309319.

YOUNG P., WILSON S., ARCH J. R. S., 1984. Prolonged $\beta$-adrenoceptor stimulation increases the amount of GDP-binding protein in brown adipose tissue mitochondria. Life Sci, 34, 11111117.

YOUNG P., KING L., CAWTHORNE M. A., 1985. Increased insulin binding and glucose transport in white adipocytes isolated from C57B $1 / 6 \mathrm{ob} / \mathrm{ob}$ mice treated with the thermogenic $\beta$ adrenoceptor agonist BRL-26830. Biochem. Biophys. Res. Commun., 133, 457-461.

YANDA R., SUMMERS R. W., 1983. Activity fronts in fed dogs : effect of a $\beta$-adrenergic agonist. Am. J. Physiol., 245, G647-G650.

ZORZANO A., BALON T. W., GARETTO L. P., GOODMAN M. N., RUDERMAN N. B., 1985. Muscle $\alpha$-aminoisobutyric acid transport after exercise : enhanced stimulation by insulin. $A m$. J. Physiol., 248, E546-552.

ZORZANO A., BALON T. W., GOODMAN M. N., RUDERMAN N. B., 1986. Additive effects of prior exercise and insulin on glucose and AIB uptake by rat muscle. Am. J. Physiol., 251, E21-E26. 